\title{
MEDIO SIGLO EN LA EVOLUCIÓN DE LOS PAISAJES NATURALES Y AGRARIOS DE SIERRA NEVADA (ESPAÑA)
}

\author{
Yolanda Jiménez Olivencia \\ Laura Porcel Rodríguez \\ Andrés Caballero Calvo \\ Instituto de Desarrollo Regional de la Universidad de Granada \\ yjimenez@ugr.es, Iporcel@ugr.es, andrescaballero@ugr.es
}

\section{RESUMEN}

Los cambios en los modos de vida de las comarcas de Sierra Nevada, las nuevas funciones que se les atribuyen y el efecto de políticas sectoriales, como la forestal o la de protección de la naturaleza, han significado profundas mutaciones en el modelo de ordenación del territorio y del paisaje.

Este artículo analiza la evolución de los paisajes desde mediados del S. XX, apoyándose en la lectura de las series de fotografías aéreas de 1956 y 2006, para determinar la naturaleza y magnitud de las transformaciones paisajísticas y relacionarlas con los procesos derivados de la crisis de la economía tradicional, las nuevas aspiraciones y demandas sobre los recursos de la montaña y la implantación actual de paradigmas tales como el de la multifuncionalidad del mundo rural o el desarrollo rural sostenible.

Palabras clave: montaña mediterránea, evolución del paisaje, espacios protegidos, Sierra Nevada.

\section{ABSTRACT}

Changes in the ways of living in the Sierra Nevada region, its new functions as well as the effects of sectoral policies, such as forestry or protection measures, have led to profound changes in the planning model and the landscape.

Fecha de recepción: abril 2013.

Fecha de aceptación: diciembre 2013. 
This paper, based on the analysis of the aerial photographs of 1956 and 2006, analyses landscape evolution in order to determine the nature and magnitude of the landscape transformations and to relate them to processes derived from the crisis in the traditional economy, the current demands for the mountain resources and new paradigms, such as multifunctionality of the rural world and the sustainable rural development.

Keywords: Mediterranean mountain, landscape change, protected areas, Sierra Nevada.

\section{INTRODUCCIÓN}

El paisaje es un concepto complejo susceptible de ser abordado desde numerosas perspectivas en tanto que en él cohabitan lo natural y lo cultural, el presente y el pasado, lo objetivo y lo subjetivo, lo real y lo imaginado. Consciente de dicha complejidad, el Convenio Europeo del Paisaje recoge la necesidad de abordar el estudio y tratamiento del paisaje atendiendo a todas sus dimensiones y facetas. En esta línea, numerosos autores (Bertrand, 2008; Gómez, 1999; Mata et al., 2003; Molinero et al., 2011; Zoido, 2012) reconocen a los paisajes como resultante de las formas del territorio y su trayectoria histórica, así como de las percepciones y representaciones de dicho territorio a través del tiempo. Unos planteamientos, crecientemente integradores, que han impulsado líneas de trabajo diversas, pero complementarias, tales como la que se interesa por la vertiente dinámica del paisaje, en la que se centra el presente trabajo.

Partimos de la idea de que la construcción del paisaje está determinada por la sucesión de los modelos socio-territoriales propios de cada momento histórico y que los cambios en las estructuras productivas y en la valoración del espacio de cada sociedad constituyen un factor explicativo de primera magnitud en la comprensión de las modificaciones, más o menos progresivas o traumáticas, que experimentan los paisajes. Por lo demás, la plasmación formal de cada modelo social y económico en el territorio pasa por la asignación de funciones diversas a cada porción del espacio, dando como resultado un mosaico característico de usos del suelo y coberturas vegetales.

Nuestra posición respecto a la necesidad del estudio diacrónico nos acerca a los planteamientos de toda una serie de trabajos (Alario et al., 2011; Araque, 2013; Giménez, 2008; López, 2004; Mata, 1997) que en España abordan el estudio de los paisajes agrarios y que encuentran en la historia las claves para explicar la génesis de sus estructuras actuales. Por otro lado, el análisis sistemático de los usos y coberturas del suelo, como método para identificar y cuantificar las principales dinámicas de cambio en el paisaje, es una práctica común en numerosas investigaciones que sobre la evolución del paisaje en el último medio siglo se vienen realizando, tanto a escala de las montañas mediterráneas españolas (Arnáez et al., 2010; Lasanta et al., 2005; Vila et al., 2009), como de los espacios montañosos a nivel internacional (Fox y Vogler, 2005; Lambin et al., 2003; Turner et al., 2003).

La evolución del paisaje de las montañas españolas desde mediados del S. XX está íntimamente relacionada con los cambios sociales, económicos, demográficos y culturales que empezaron a manifestarse en los años 50 y que se concretan básicamente en procesos de despoblamiento, de abandono de las actividades campesinas y de empobrecimiento de las formas de vida rural. 
La caída de la población y la falta de competitividad de la agricultura de montaña en la nueva economía industrial significaron el cese de la fuerte presión que las comunidades rurales ejercían sobre los recursos. La desarticulación del modo de vida y de explotación tradicional significó también una falta de gestión del territorio montañés, que hasta entonces había estado sometido a un ordenamiento sistemático de los usos del suelo, de los recursos forestales y del ciclo del agua. Esta progresiva desaparición de la actividad humana ha generado una serie de efectos negativos que afectan a la estabilidad de las vertientes, la biodiversidad, la vulnerabilidad frente a incendios forestales y la calidad del paisaje, en la medida en que éste tiende a la homogeneización y acusa la degradación del patrimonio cultural asociado a las actividades tradicionales (Arnáez et al., 2010; Jiménez, 2010; Swihart y Moure, 2004). Los diversos sistemas de gestión de los recursos y ordenación del espacio propiciaron a lo largo de la historia la configuración de paisajes de marcado carácter cultural. Era por tanto esperable que un cambio brusco en las condiciones de la ocupación y gestión humana del territorio significase una crisis en los frágiles equilibrios de la montaña y un efecto, más o menos diferido en el tiempo, de transformación de los paisajes. Hernández y Giménez (2011) reconocen que las transformaciones habidas en el campo español desde mediados del S. XX han dejado una huella inusitada en el paisaje.

Nuestro objetivo en este artículo consiste en analizar cómo ha afectado a las comarcas de Sierra Nevada la crisis económica y social que se desencadenó en los años 50 y cómo los cambios del modelo socio-territorial han derivado en una dinámica de transformación del paisaje tan profunda que amenaza con la pérdida de sus valores ambientales, culturales y estéticos.

\section{METODOLOGÍA Y FUENTES UTILIZADAS}

Para abordar este estudio de carácter evolutivo, hemos delimitado inicialmente los grandes tipos de paisaje de Sierra Nevada, con objeto de establecer para cada uno de ellos sus principales dinámicas de cambio. Los cuatro tipos resultantes proceden de la agrupación de los geosistemas que fueron identificados en 1991 por Jiménez Olivencia (figura 1). Dicha agrupación se fundamenta en las semejanzas que en cada conjunto de geosistemas presenta el modelo de organización espacial de las actividades y de los asentamientos, lo que se refleja además en las peculiaridades de la imagen proyectada.

El análisis diacrónico se concreta en el estudio de los cambios experimentados por las coberturas del suelo entre 1956 y 2006 en cada uno de los grandes tipos de paisaje mencionados. Para ello hemos acudido a la fotointerpretación de las imágenes de 1956 del vuelo americano y de 2006 de la Junta de Andalucía. El proceso de fotointerpretación ha estado sujeto a un permanente control, por contraste de ambas imágenes entre sí y con otros documentos fotográficos ${ }^{1}$. También hemos recurrido a la consulta de series de mapas como la de Cultivos y Aprovechamientos del Ministerio de Agricultura y Pesca de los años 70 y 80 y a los Mapas topográficos de Andalucía 1:10.000. El trabajo de campo nos ha permitido además el control de una serie de puntos clave para validar las hipótesis de fotointerpretación.

1 Ortofotografía de Andalucía a color de 1998 y Ortofotografía Digital de Andalucía, serie provincial b/n 2001 y color de 2004 y 2006. Instituto de Cartografía de Andalucía. 
Tras el análisis de las dos imágenes aéreas se han elaborado sendos mapas de coberturas del suelo utilizando el programa ArcGis 9.3 de ESRI España S.A., por asignación a cada uno de los polígonos diferenciados de uno de los 40 atributos que conforman la leyenda final (tabla 1).

Tabla 1

COBERTURAS DEL SUELO IDENTIFICADAS EN LA LEYENDA

\begin{tabular}{|c|l|c|l|}
\hline $\mathbf{1}$ & Quercíneas & $\mathbf{2 1}$ & Regadíos leñosos \\
\hline $\mathbf{2}$ & Coníferas & $\mathbf{2 2}$ & Regadíos herbáceos y leñosos \\
\hline $\mathbf{3}$ & Otras frondosas & $\mathbf{2 3}$ & Regadíos herbáceos con vegetación natural \\
\hline $\mathbf{4}$ & Mezclas de coníferas y quercíneas & $\mathbf{2 4}$ & Regadíos leñosos con vegetación natural \\
\hline $\mathbf{5}$ & Bosque galería & $\mathbf{2 5}$ & Regadíos herbáceos y leñosos con vegetación natural \\
\hline $\mathbf{6}$ & Matorral con quercíneas & $\mathbf{2 6}$ & Secanos herbáceos \\
\hline $\mathbf{7}$ & Matorral con coníferas & $\mathbf{2 7}$ & Secanos leñosos \\
\hline $\mathbf{8}$ & Matorral con otras frondosas & $\mathbf{2 8}$ & Secanos herbáceos y leñosos \\
\hline $\mathbf{9}$ & Matorral con mezclas de coníferas y quercíneas & $\mathbf{2 9}$ & Secanos herbáceos con vegetación natural \\
\hline $\mathbf{1 0}$ & Pastizal con quercíneas & $\mathbf{3 0}$ & Secanos leñosos con vegetación natural \\
\hline $\mathbf{1 1}$ & Pastizal con coníferas & $\mathbf{3 1}$ & Secanos herbáceos y leñosos con vegetación natural \\
\hline $\mathbf{1 2}$ & Pastizal con otras frondosas & $\mathbf{3 2}$ & Urbano \\
\hline $\mathbf{1 3}$ & Pastizal con mezclas de coníferas y quercíneas & $\mathbf{3 3}$ & Industrial y comercial \\
\hline $\mathbf{1 4}$ & Matorral denso & $\mathbf{3 4}$ & Minero \\
\hline $\mathbf{1 5}$ & Matorral con pasto y roca o suelo & $\mathbf{3 5}$ & Balsas y canales de riego \\
\hline $\mathbf{1 6}$ & Pastizal continuo & $\mathbf{3 6}$ & Red de carreteras \\
\hline $\mathbf{1 7}$ & Pastizal con claros & $\mathbf{3 7}$ & Otras infraestructuras técnicas \\
\hline $\mathbf{1 8}$ & Áreas con fuertes procesos erosivos & $\mathbf{3 8}$ & Lagunas continentales \\
\hline $\mathbf{1 9}$ & Roquedos y suelos desnudos & $\mathbf{3 9}$ & Cortafuegos \\
\hline $\mathbf{2 0}$ & Regadíos herbáceos & $\mathbf{4 0}$ & Otros \\
\hline
\end{tabular}

Fuente: Elaboración propia.

A partir de los mapas de coberturas del suelo de 1956 y 2006 se procedió a obtener las superficies correspondientes a cada año, comparándolas e identificando las dinámicas de cambio en el periodo analizado.

La herramienta utilizada fue la interfaz de ArcToolBox ModelBuilder de ArcGis 9, que permite optimizar la construcción de modelos de geoprocesamiento en un entorno gráfico.

Con los dos mapas de partida a modo de inputs, se diseñó un diagrama de flujo compuesto por herramientas de geoprocesamiento, datos y capas secundarias combinadas. Así obtuvimos los mapas y tablas alfanuméricas necesarias para el análisis posterior de los cambios. 


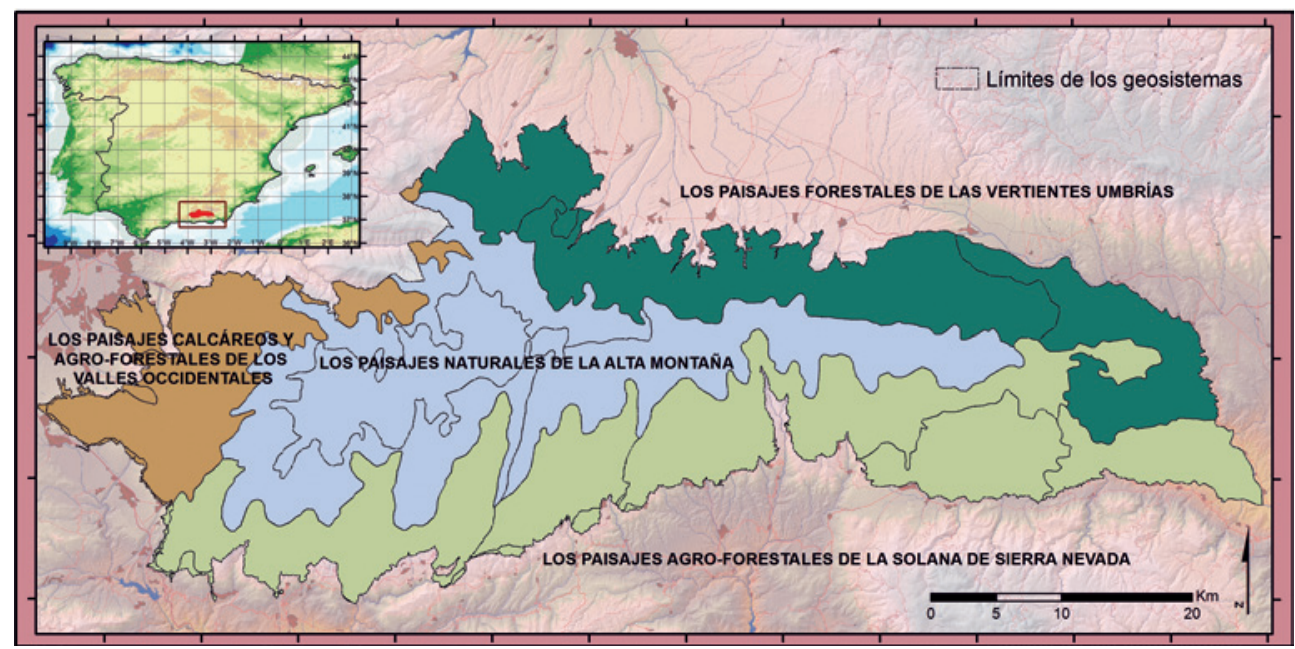

Fuente: Elaboración propia.

Las tablas y mapas de dinámicas nos muestran no sólo el alcance de las transformaciones del mosaico de coberturas, sino también cuál ha sido la naturaleza de estos cambios. Es decir, nos indican qué categorías han venido a sustituir a aquéllas existentes en la fecha de partida y en qué proporción. De este modo podemos hacer cálculos exactos de las superficies sometidas a transformación y averiguar cuáles son las coberturas del suelo que han perdido protagonismo en la configuración de cada paisaje y cuáles otras han ocupado su lugar (Augustin et al., 2001; Robinson y Brown, 2009, Turner et al., 1994; Varga y Vila, 2006).

\section{LOS PAISAJES TRADICIONALES DE SIERRA NEVADA A MEDIADOS DEL SIGLO XX}

\section{III.1. Bases ecológicas y culturales}

El macizo montañoso de Sierra Nevada presenta una línea de cumbres continua y de gran extensión que se alarga de oeste a este a modo de gran eje axial. Dicho eje la divide en dos grandes vertientes, la solana, abierta a las influencias del mar Mediterráneo, y la umbría, que mira hacia el interior. Las mayores alturas se alcanzan en el sector centro-occidental, donde se rebasan los $3000 \mathrm{msm}$ (Pico Mulhacén, $3481 \mathrm{~m}$ ).

Desde el punto de vista climático, considerando el espacio seco-semiárido que lo rodea, el macizo constituye una isla pluviométrica donde se recoge una media de $1200 \mathrm{~mm}$ anuales de precipitación en el piso de alta montaña. Su elevada altitud y su baja latitud la convierten en un espacio de transición entre las montañas áridas de latitudes tropicales y las húmedas de latitudes templadas.

Las condiciones geo-ambientales están muy condicionadas por la fuerte aridez del verano, siendo éste uno de los factores físicos que explican en mayor medida el modelo de 
organización humana. En Sierra Nevada el déficit hídrico afecta al menos a tres meses consecutivos, durante los que sólo es posible el desarrollo de pastizales muy mediocres que no han podido sostener una actividad ganadera relevante.

Paralelamente, una serie de condicionantes del medio natural que tienen que ver con el predominio de rocas silíceas de carácter semipermeable y relativamente blandas, como los micaesquistos, han favorecido la extensión de los cultivos. La actividad agraria ha aprovechado las vertientes con exposición solana, que permiten la reducción de la incidencia de las heladas, así como el ciclo local del agua propio de un régimen de carácter nivopluvial (Castillo, 2010).

Sobre la base de estas condiciones físicas se constituyeron distintos sistemas de explotación de los recursos naturales basados en una organización agro-silvo-pastoril que, ligada casi siempre a la subsistencia, maximizaba las capacidades del medio (Rodríguez, 1981). Estos modelos tradicionales de explotación de los recursos y ordenación del espacio se mantuvieron operativos hasta los años 50-60. En esta situación, en la que los equilibrios naturales habían sido fuertemente intervenidos y en la que los recursos de la montaña no resultaban fácilmente movilizables, las estrategias de adaptación y uso múltiple habían configurado agrosistemas estables cuyo aspecto visible mostraba un mosaico equilibrado de espacios mixtos, forestales y agrarios.

El más extenso y complejo de los sistemas de puesta en valor de los recursos de toda Sierra Nevada es el de la comarca de la Alpujarra. En los soleados valles alpujarreños el modelo de ordenación de las actividades campesinas se caracterizaba por responder a una sucesión altitudinal de los usos del suelo y por una integración de los aprovechamientos agrícolas, ganaderos y silvícolas.

Desde el fondo de los valles hasta los $1400 \mathrm{~m}$ aproximadamente se extienden las vegas de los pequeños pueblos, que constituyen una amplia zona regada compuesta de campos escalonados de pequeñas dimensiones. Los terrenos son aquí muy abruptos y por ello se han visto sometidos a un minucioso acondicionamiento basado en la construcción de terrazas que se adaptan a las condiciones micro-topográficas y corrigen el sistema de pendientes original. Las terrazas o bancales constituyen infraestructuras básicas de la ingeniería tradicional que se complementan con una extensa red de canales o acequias. En estos campos de regadío se cultivaban sobre todo herbáceos, si bien en el borde de las parcelas era frecuente la plantación de árboles frutales o forestales que permitían diversificar la producción y sujetar el terreno.

Por encima del espacio verde del regadío se situaban los campos de secano, con una trama parcelaria menos compleja y una menor repercusión en la economía agraria. El secano alcanzaba los 1600-1800 m y, por encima de éste, dominaban los pastos de verano o «agostaderos», que eran la base de la alimentación del ganado. Incluso a estas alturas podían encontrarse campos de cultivo temporal de primavera-verano situados alrededor de los cortijillos de montaña que llegaban a alcanzar los $2200 \mathrm{~m}$. Los pastos y bosques de la zona alta de los valles permitían una actividad complementaria. El ganado menor pasaba el verano en estos pastos de altura y el invierno en los de la cercana costa, según un sistema de trashumancia de características similares a otros practicados en toda España. Las masas forestales, que formaban un límite discontinuo con los pastos y los cultivos, eran también objeto de aprovechamientos diversos. 
Frente a la realidad socioeconómica que caracterizó a la comarca alpujarreña hasta los años 50, la vertiente norte de Sierra Nevada apenas ha estado sometida al uso agrario. La dedicación mayoritaria de las tierras ha sido la forestal y la ganadera, si bien esta última sólo ha alcanzado verdadera relevancia en algunas zonas de dehesa para reses bravas.

Por su parte la vertiente occidental del macizo presentaba una economía rural de subsistencia en donde los pequeños regadíos y secanos, fundamentalmente arbóreos, alternaban con especies del bosque original de encinas, robles y arces o de ribera. La vida rural se completaba con la explotación ganadera de las dehesas altas y los pastos de altura.

La combinación de los caracteres físicos y biológicos de la montaña y del ordenamiento de los usos agro-forestales configuró en Sierra Nevada un mosaico de paisajes que responden a los cuatro grandes tipos de la figura 1: paisajes de marcado carácter natural situados sobre el límite superior del árbol; forestales que se extienden ampliamente sobre la vertiente norte; agroforestales que ocupan los valles del sur; y calcáreos y agro-forestales en los valles occidentales.

\section{III.2. El estado de los paisajes en la década de los 50}

El contexto socio-económico y cultural de los años 50 y las herencias de un pasado aún más lejano permiten comprender las características propias de los paisajes de mediados del siglo XX.

Con carácter general, en el paisaje destacaban las extensas superficies de matorrales y pastizales, que alcanzan un $62 \%$ de la superficie total (figura 2). Estos dominaban las áreas situadas por encima del límite del árbol, mientras en los tramos medios y bajos de los valles se mezclaban con el espacio cultivado y los escasos bosquetes de frondosas mediterráneas, muy reducidos tras un proceso secular de deforestación. Los espacios naturales arbolados ocupaban apenas el 15,3\% del macizo. El paisaje de las laderas medias aparecía así marcado por una sucesión rítmica de formaciones de monte cubriendo los espacios de interfluvio, especialmente de monte bajo, y de campos de cultivo en terrazas que tapizaban los valles en convivencia estrecha con la vegetación natural e integrando, en la propia trama parcelaria, elementos de carácter forestal. Los espacios cultivados ocupaban entonces un 17,4\% de la superficie total del macizo.
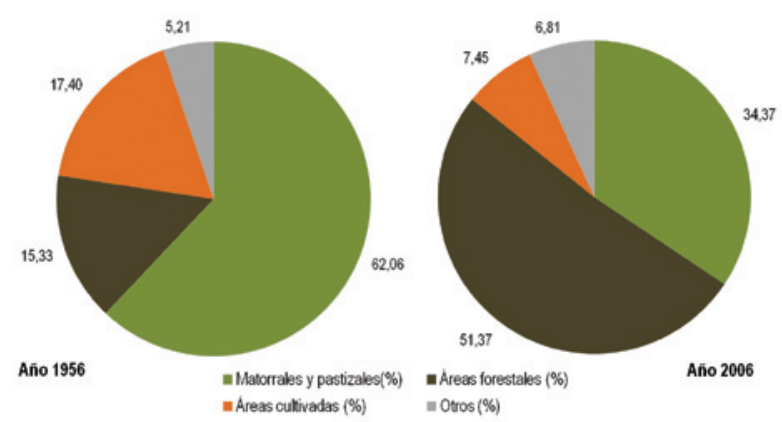
Para caracterizar la situación en 1956, nos referiremos sucesivamente al estado de cada uno de los cuatro grandes tipos de paisaje que hemos identificado, aludiendo a los distintos geosistemas que los integran.

\section{III.2.1. Los paisajes naturales de la alta montaña}

Son aquellos situados por encima de los $2200 \mathrm{~m}$ de altitud aproximadamente. El primero de estos paisajes coincide con el piso Crioromediterráneo, donde el máximo potencial biológico corresponde a un pastizal xérico muy discontinuo que se desarrolla sobre litosuelos que sufren fenómenos de periglaciarismo activo. En este geosistema se reconocen morfologías heredadas de origen glaciar, como pequeños circos, glaciares rocosos, lagunas, etc.

Tabla 2

COBERTURAS DEL SUELO EN 1956 EN LOS PAISAJES NATURALES DE LAALTA MONTAÑA

\begin{tabular}{|l|c|c|}
\cline { 2 - 3 } \multicolumn{1}{c|}{} & ha & \% \\
\hline Matorrales y pastizales & 47439,85 & 86,68 \\
\hline Superficies boscosas & 13,69 & 0,03 \\
\hline Roquedo, suelo desnudo y áreas erosivas & 5407,8 & 9,88 \\
\hline Áreas cultivadas & 1337,25 & 2,44 \\
\hline Otros usos & 532,35 & 0,97 \\
\hline
\end{tabular}

Rodeando al espacio de cumbres, en la alta montaña se desarrollan otros dos geosistemas. En ambos, las vertientes montañosas de topografía relativamente suave aparecen cubiertas mayoritariamente de matorrales densos del piso oromediterráneo que han propiciado la formación de suelos orgánicos sobre grandes extensiones de canchales de origen periglaciar.

En los años 50 estos espacios estaban escasamente intervenidos por la sociedad rural, que se limitaba al pastoreo de ovejas y cabras en los pastizales siempre húmedos del entorno de lagunas y arroyos, así como en los pastizales oromediterráneos de menor calidad, donde ocasionalmente se desarrollaban prácticas de fuego pastoral destinadas a favorecer el crecimiento de las gramíneas.

En general, los paisajes mantenían un carácter marcadamente natural con predominio de las geofacies de matorral climácico con importante cobertura del suelo y de las de pastizal frío y seco con escasa cobertura y gran riqueza florística. Aunque con una localización de carácter más puntual, las geofacies correspondientes a pastizales higrófilos constituían elementos de gran significación ecológica y estética dentro de los paisajes líticos de las cabeceras.

\section{III.2.2. Los paisajes forestales de las vertientes umbrías}

Los paisajes forestales se extendían por la vertiente norte de Sierra Nevada desde los 2.200 metros hasta la base de la montaña, situada a unos 850 metros de altitud aproximadamente.

Los micaesquistos aparecen aquí modelados por una red de cursos fluviales de montaña paralelos que dejan entre sí grandes interfluvios o lomas de perfil topográfico suave. 
Sobre estas laderas silíceas se extendían a mediados del siglo XX grandes superficies de matorral y pastizal que venían a sustituir a los antiguos bosques de robles y encinas del piso supra-mediterráneo, más húmedo y frío, y a los encinares meso-mediterráneos de las zonas más bajas y térmicas con ombroclima seco. Los procesos continuados de explotación forestal explican que estas formaciones vegetales de degradación llegaran a alcanzar entorno al $56,1 \%$ de toda la superficie, en tanto que las frondosas del bosque original apenas alcanzaban el $21,1 \%$ (ver tabla 3 ). Éstas sobrevivían en la medida en que eran fuente indispensable para la provisión de leñas de los pueblos situados en el pie de monte de la sierra, generando así pequeñas geofacies arboladas en el entorno de las poblaciones.

El tercer tipo de geofacies que diversificaban estos paisajes se correspondía con campos de cultivo extensivo de cereales de secano.

Tabla 3

COBERTURAS DEL SUELO EN 1956 EN LOS PAISAJES FORESTALES DE LA UMBRÍA

\begin{tabular}{|l|c|c|}
\cline { 2 - 3 } \multicolumn{1}{c|}{} & ha & \% \\
\hline Matorrales y pastizales & 22373,29 & 56,15 \\
\hline Superficies boscosas & 8420,73 & 21,13 \\
\hline Áreas cultivadas & 8616,64 & 21,62 \\
\hline Otros usos & 438,24 & 1,10 \\
\hline
\end{tabular}

\section{III.2.3. Los paisajes calcáreos y agro-forestales de los valles occidentales}

En la porción occidental de la sierra que se extiende desde los $2200 \mathrm{~m}$ hasta la depresión de Granada, los paisajes pueden agruparse en dos grandes tipos, los que se desarrollan sobre rocas calcáreas y aquéllos que lo hacen sobre rocas silíceas.

Los primeros están marcados por la naturaleza de las rocas calizas y dolomíticas. La escasa aptitud de estos terrenos para la agricultura determinó la práctica ausencia de asentamientos permanentes. La energía natural domina estos terrenos de morfogénesis muy activa limitando fuertemente la creación de suelo y la sucesión vegetal. Tras un largo proceso de deforestación el paisaje se caracterizaba en los años 50 por el dominio de un matorral bajo y disperso (ver tabla 4) muy adaptado a suelos rejuvenecidos por constantes procesos de erosión. Ocasionalmente podían encontrarse restos del pinar-sabinar autóctono, cuya área de distribución había quedado extraordinariamente restringida.

Tabla 4

COBERTURAS DEL SUELO EN 1956 EN LOS PAISAJES CALCÁREOS YAGRO-FORESTALES DE LOS VALLES OCCIDENTALES

\begin{tabular}{|l|c|c|}
\cline { 2 - 3 } \multicolumn{1}{c|}{} & ha & \% \\
\hline Matorrales y pastizales & 11551,83 & 59,06 \\
\hline Superficies boscosas & 5228,28 & 26,73 \\
\hline Áreas cultivadas & 2361,52 & 12,07 \\
\hline Otros usos & 416,65 & 2,13 \\
\hline
\end{tabular}


Ocupando una superficie mucho más reducida se configuraba un modelo de paisaje muy diferente sobre la base de un sustrato de rocas esquistosas y en condiciones más húmedas y frescas. Las poblaciones asentadas en la cabecera del río Genil propiciaron una ordenación del espacio según la cual la parte alta de los valles mantenía extensas zonas de matorral y pastizal para la alimentación del ganado junto a dehesas más o menos arboladas.

Por debajo de estos ámbitos y mezclándose con ellos aparecía un paisaje agro-forestal original formado por masas de árboles y arbustos con robles, fresnos, servales, arces, etc. Ladera abajo, estas masas conectaban con terrazas escalonadas cubiertas por cultivos de regadío de carácter arbóreo como castaños, nogales o cerezos, que propiciaban una transición progresiva y permitían una sensación ininterrumpida de espacio arbolado.

La disposición este-oeste de estos valles significaba la alternancia de laderas umbrías, con densa cobertura vegetal, y laderas de solana que no respondían al modelo de paisaje antes descrito. Al contrario que las de umbría, estas vertientes presentaban signos de fuerte deterioro ambiental. Sus ecosistemas originales estaban muy alterados por la mayor deforestación de los terrenos, la fuerte xericidad ambiental y la escasa presencia de cultivos arbóreos en los campos.

\section{III.2.4. Los paisajes agro-forestales de la solana de Sierra Nevada}

El último modelo paisajístico, el más complejo y el de mayor valor histórico-patrimonial y simbólico, es resultado del sistema de explotación tradicional descrito al referirnos a la comarca alpujarreña. El paisaje de las vertientes meridionales podía calificarse de agroforestal atendiendo a dos consideraciones. En primer lugar, los espacios cultivados significaban el 30,5\% de su extensión (ver tabla 5) y, en segundo término, las masas forestales se mezclaban con el espacio cultivado ocupando los mismos tramos altitudinales y siendo objeto de aprovechamientos forestales y ganaderos de carácter complementario. Los campos, especialmente los destinados al cultivo del cereal, llegaban a ocupar altitudes extremas, sustituyendo a las masas forestales en terrenos de muy escaso potencial para la actividad agrícola. La presión de la agricultura de subsistencia se hacía visible en la escasez de masas de bosque, que se refugiaban en los terrenos más pendientes y en los suelos más rocosos de los valles. Es cierto que pequeñas y medianas áreas de vegetación natural pervivían en el espacio cultivado, al igual que árboles de carácter agro-forestal como castaños, nogales o almeces, que mantenían una importante presencia. Sin embargo, otros elementos naturales del paisaje como los bosques de ribera quedaron reducidos en muchos de los valles a estrechas franjas junto a los cursos de los ríos (Guillerme, et al., 2013).

Tabla 5

COBERTURAS DEL SUELO EN 1956 EN LOS PAISAJES AGRO-FORESTALES DE LA SOLANA DE SIERRA NEVADA

\begin{tabular}{|l|c|c|}
\cline { 2 - 3 } \multicolumn{1}{c|}{} & ha & \% \\
\hline Matorrales y pastizales & 25164,03 & 43,74 \\
\hline Superficies boscosas & 11212,81 & 19,49 \\
\hline Áreas cultivadas & 17559,38 & 30,52 \\
\hline Otros usos & 3589,72 & 6,24 \\
\hline
\end{tabular}


Por lo que se refiere al ámbito no cultivado, aparecía dominado por extensas formaciones de matorral de degradación del bosque original. Los restos del bosque autóctono eran escasos, un 19,4\%, como resultado de la expansión de los cultivos pero también de la actividad minera de las sierras vecinas. Estas masas forestales de encinas y robles no respondían a su estado clímax potencial, pudiendo ser definidas como extensiones de monte bajo con arbolado disperso.

La intensidad del aprovechamiento humano durante el periodo autárquico se basaba en el esfuerzo ímprobo de los agricultores y en la utilización sistemática de los recursos en un momento en el que el atraso económico del país y la dinámica expansiva de la población propiciaron un máximo de ocupación de la tierra (Rodríguez, 1981; García, 1999).

\section{LOS PAISAJES TRAS MEDIO SIGLO DE CAMBIOS EN LA VIDA RURAL DE LA MONTAÑA}

\section{IV.1. Crisis de la economía tradicional y nuevas funciones para los espacios montañosos}

Sobre la base del sistema tradicional de explotación descrito, las montañas españolas mantuvieron una intensa actividad económica y una considerable densidad de población hasta los años 50. A partir de ese momento, el proceso tardío de industrialización en España significó una profunda quiebra del mundo rural y en especial de la montaña. La pequeña escala productiva y el modelo de autoabastecimiento se mostraron incapaces de adaptarse a la nueva situación del país, que conoció en poco tiempo cambios muy profundos. La emigración hacia las ciudades y regiones industriales de España y de Europa fue entonces el máximo exponente de la crisis. El éxodo rural fue especialmente intenso en los pequeños pueblos de montaña, máxime en una región como la andaluza, que presentaba una clara situación de subdesarrollo (García y Ocaña, 1990). La profundidad del proceso de despoblación, entre 1950 y 1975, puede verse en la figura 3:

Figura 3

EVOLUCIÓN DE LA POBLACIÓN DE SIERRA NEVADA

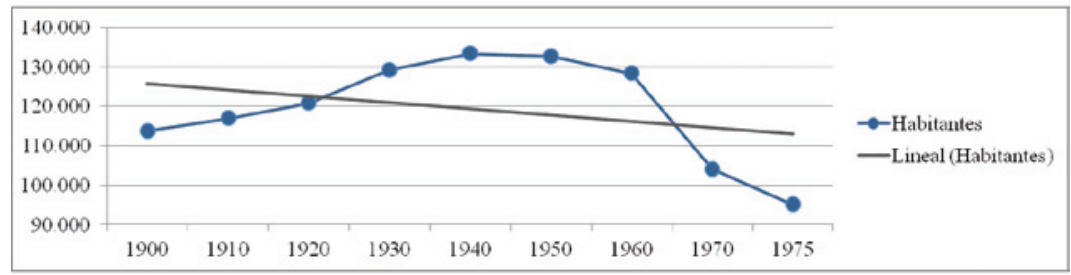

Fuente: Cózar, 2000.

La fuerte pérdida de efectivos agrarios significó un abandono generalizado de las actividades tradicionales, quedando baldíos multitud de campos en las laderas de Sierra Nevada. Primero las tierras de menor capacidad agronómica y más difícil acceso, y luego las parcelas más productivas del regadío, dejaron de cultivarse. Todo ello provocó el deterioro de las bases materiales del sistema de explotación tradicional (García, 1999). Los aterrazamientos comenzaban a derrumbarse, los campos se cubrían de matorral y la red de acequias se dete- 
rioraba por falta de mantenimiento y por la amenaza que se cernía sobre la ordenación sistemática y ancestral del reparto del agua. Cabe destacar que otros intereses más potentes, como la agricultura intensiva o los usos turístico-residenciales del agua en la costa, presionaban sobre los recursos propios de la montaña (Rodríguez, 2000).

En definitiva, la desarticulación del modelo productivo de los pueblos de Sierra Nevada contribuyó a una transformación lenta pero continuada de los paisajes agro-forestales de muchos municipios de la sierra, especialmente de aquellos situados en la Alpujarra y en el valle del Genil.

Ligadas parcialmente a la desaparición de las prácticas culturales, en buena parte de la sierra las políticas forestales de la época también incidieron en una fuerte transformación de los paisajes de Sierra Nevada. Es el momento en el que se ponen en marcha ambiciosas campañas de reforestación que se enmarcan en los programas de la política hidrológico-forestal a nivel nacional. Su propósito era la recuperación de amplios espacios para el desarrollo del bosque, que permitiría además frenar los graves problemas de erosión de las vertientes y la pérdida de suelos. Los fenómenos erosivos podrían llegar a poner en peligro la funcionalidad a medio-largo plazo de los grandes embalses construidos aguas abajo. Además la recurrencia de fenómenos catastróficos, como las inundaciones que afectaban a distintas poblaciones de la Alpujarra (Iglesias, 1985), aconsejaban incrementar las zonas forestales en las cabeceras de los valles. En este contexto las vertientes septentrionales conocieron una transformación radical de sus paisajes por efecto de la reforestación sistemática de las laderas desde la base misma del macizo hasta los $2000 \mathrm{~m}$ de altitud.

En las vertientes sur y occidental buena parte de los sectores elevados también fue ocupada por distintas formaciones de pinar, parcialmente extendidos por campos de cultivo abandonados.

El proceso de abandono del campo conoció un cambio de coyuntura hacia 1975. Con carácter general, la crisis económica mundial significó una interrupción de las corrientes migratorias y ello permitió a un gran número de municipios rurales andaluces recomponerse parcialmente (Ocaña, 2000). Esta circunstancia no tuvo sin embargo gran repercusión en los municipios montanos.

Mientras que Andalucía, desde la etapa alcista de mediados de los 80, mantiene una evolución positiva de la economía y el bienestar, muchos municipios de montaña pierden población en favor de las dinámicas áreas metropolitanas y de las comarcas litorales andaluzas. A pesar de la ralentización de las pérdidas, 4000 personas durante los años 80 frente a 16000 en los 70, avanza la crisis demográfico-social por efecto del progresivo envejecimiento de la sociedad rural de la montaña. Se alimenta así el abandono de la actividad campesina de forma que los paisajes agrarios sufren importantes deterioros y acaban perdiendo su protagonismo en amplios sectores.

En los años 80 los municipios de Sierra Nevada se caracterizaban por un importante agotamiento demográfico y por la incapacidad de reactivación del sistema productivo tradicional. A falta de alternativas económicas, los pueblos resisten gracias a la mayor atención social de la que son objeto por parte de la administración, cuyas ayudas constituyen un capítulo básico en la economía de las familias. También las ayudas especiales para la agricultura de montaña tuvieron algunos efectos positivos en la comarca de la Alpujarra, iniciándose así una tendencia hacia la generalización de la agricultura asistida. 
$\mathrm{Al}$ margen de la agricultura, la única expectativa de desarrollo económico que se plantea se relaciona con el potencial turístico del macizo en sus dos versiones: turismo deportivo y turismo rural. El primero se desarrolla en las altas cumbres occidentales junto a la estación de deportes de invierno. El segundo aparece con carácter pionero en algunos municipios de la Alpujarra (Consejería de Medio Ambiente, 2007).

Por su parte la intervención de los poderes públicos sobre el espacio de monte, que hasta entonces se había manifestado a través de la política forestal, se refuerza con la inclusión de Sierra Nevada en el catálogo de espacios a proteger del Plan Especial de Protección del Medio Físico de la Provincia de Granada y, más tarde, con la aparición de la Ley Andaluza de Inventario de Espacios Naturales de 1989, a partir de la cual Sierra Nevada es declarada Parque Natural. Poco después, en 1999, Sierra Nevada alcanzará el reconocimiento de Parque Nacional. La política de conservación consideró desde el principio la necesidad de hacer compatible la conservación con los usos tradicionales y con el desarrollo rural. No obstante, las acciones llevadas a cabo han tenido un carácter excesivamente centralizado, poco planificado y puntual, de modo que casi siempre han sido efectuadas ignorando las demandas locales, siendo fuente de tensiones y frustraciones diversas (Rodríguez, 2000). En las últimas décadas el esfuerzo de los gestores del espacio protegido por apoyar el desarrollo local y promocionar el reconocimiento de los valores de la sierra entre la población local ha tenido resultados desiguales. Según se desprende de las encuestas realizadas por Píñar (2008), el conflicto conservación-desarrollo no ha desaparecido, de modo que aún hoy se mantiene entre una parte sustancial de los agricultores la percepción de que el Parque no favorece la práctica de la agricultura. Sin embargo, los empresarios del sector turístico opinan que su actividad se beneficia de la existencia del espacio protegido.

A partir de los años 90 se fue abriendo paso desde el gobierno regional un nuevo paradigma impulsado por las directivas europeas. Según esta filosofía, el desarrollo rural en áreas de montaña no puede basarse únicamente en la agricultura sino en el conjunto de los recursos potenciales existentes a escala local. Su movilización debe hacerse en paralelo a la conciencia ecológica y a las nuevas demandas de naturaleza y ocio de una sociedad urbana avanzada (Mulero, 1995).

En este marco del desarrollo rural sostenible y la multifuncionalidad del medio rural, las economías de los municipios de montaña siguen siendo precarias y las posibilidades reales de desarrollo muy limitadas. Al escaso capital humano con el que cuentan unos pueblos muy envejecidos se une la falta de espíritu emprendedor y una escasa voluntad de cooperación en proyectos colectivos.

La única experiencia de cierto alcance que ha tratado de poner en marcha mecanismos de desarrollo rural integral en Sierra Nevada se relaciona con las iniciativas comunitarias LEADER. Los distintos programas de evaluación de estas iniciativas llevados a cabo por la Junta de Andalucía señalan una mejora notable en las condiciones de vida de la población local (Moscoso, 2005).

En el transcurso de las últimas décadas se ha demostrado que el sector servicios ha sido el más potenciado por estas políticas, en gran medida porque la población local ha decidido impulsar los distintos sectores de la economía a partir de la actividad turística. Frente a ello, otros sectores como el de la agroindustria, la industria cárnica o la artesanía han resultado más limitados y están recibiendo un apoyo económico mucho menor. 
Hoy en Sierra Nevada las bases de la economía local parecen haberse desligado de las actividades agroganaderas. El número de exploraciones agropecuarias no ha cesado de disminuir, si bien su ritmo de desaparición parece haberse ralentizado desde 1990. De las 83 explotaciones de la Alpujarra Alta Oriental que fueron sometidas a estudio en 1981, 49 se mantenían activas una década más tarde y sólo 40 en el año 2001 (Calatrava y Sayadi, 2004).

El nuevo modelo económico que trata de promocionarse bajo la filosofía de la multifuncionalidad y la diversificación de las actividades económicas, parece haberse volcado hoy excesivamente en la promoción turística que, sin embargo, no alcanza al conjunto de las comarcas sino que se ha polarizado sobre determinados valles de la sierra que fueron pioneros en el sector. Además, el turismo rural no ha estado suficientemente conectado con el resto de los sectores económicos, de modo que apenas ha estimulado la comercialización de producciones locales de calidad.

Considerando todo lo anterior podríamos decir que la escasa capacidad del campo como motor de la economía, unido al progresivo entendimiento de las montañas como reservas de naturaleza y recursos, lugares de ocio y espacios para una economía de diversificación y pluriactividad, han significado cambios profundos en el modelo de ordenación del espacio y gestión de los recursos.

\section{IV.2. Transformaciones y estado actual de los paisajes de Sierra Nevada}

La naturaleza y alcance de las mutaciones de orden social, económico y cultural que han tenido lugar en el transcurso del último medio siglo han propiciado cambios sustanciales en el uso del territorio y, consecuentemente, en el reparto final de las coberturas del suelo en toda la sierra, tal y como aparece reflejado en la figura 2.

Las políticas públicas de reforestación han supuesto un notable incremento del bosque de coníferas que hoy se extiende por las laderas medias de manera casi continua, ascendiendo también, con carácter extraordinario, por encima del límite superior del árbol. El pinar constituye un elemento clave del paisaje actual ya que forma parte sustancial de la mayoría de los geosistemas, penetra en los espacios agrícolas situados en la periferia del área cultivada e invade incluso formaciones de matorral con arbolado disperso de encinas.

El avance generalizado de las superficies boscosas es atribuible también a procesos espontáneos de sucesión vegetal, que han propiciado la expansión o maduración del bosque de encinas y robles beneficiándose de la menor presión ejercida por el hombre en las últimas décadas. Sólo los incendios forestales han impedido una prevalencia aún mayor del bosque en el paisaje actual.

Paralelamente, la caída del volumen de población y el abandono del campo repercuten en la escasa participación que los usos agrarios tienen hoy en Sierra Nevada, apenas un 7,4\%. Especialmente las zonas aterrazadas de la comarca alpujarreña y algunos valles altos de la vertiente occidental han sufrido fuertes transformaciones. Hoy, el avance de los campos abandonados constituye un indicador clave del proceso de mutación de unos paisajes cada vez más indefinidos, cuyos contornos se desdibujan anticipando un proceso de banalización del paisaje.

Nos referiremos ahora, al igual que ya hicimos en el apartado segundo, a los cuatro grandes tipos de paisaje descritos en Sierra Nevada para identificar tanto el estado de los geosistemas como las principales dinámicas responsables de su transformación. El porcentaje global de cambio experimentado por cada tipo aparece recogido en la tabla 6 . 


\begin{tabular}{|l|c|c|}
\cline { 2 - 3 } \multicolumn{1}{c|}{} & $\begin{array}{c}\% \\
\text { conservado }\end{array}$ & $\begin{array}{c}\% \\
\text { transformado }\end{array}$ \\
\hline Paisajes naturales de la alta montaña & 76,28 & 23,72 \\
\hline Paisajes forestales de las vertientes umbrías & 27,30 & 72,70 \\
\hline Paisajes calcáreos y agro-forestales de los valles occidentales & 18,47 & 81,53 \\
\hline Paisajes agro-forestales de la solana & 32,43 & 67,57 \\
\hline Total en Sierra Nevada & $\mathbf{4 2 , 8 2}$ & $\mathbf{5 7 , 1 8}$ \\
\hline
\end{tabular}

\section{IV.2.1. Los paisajes naturales de la alta montaña}

Los paisajes de la alta montaña han mantenido en general una situación de mayor estabilidad que el resto de los entornos paisajísticos de la sierra, conservando la misma cobertura del suelo en un 76,2\% de su superficie (ver tabla 6 y figura 5).

La dinámica de los geosistemas que se configuran por encima de los $2000 \mathrm{~m}$ de altitud ha estado muy ligada a los procesos morfoclimáticos. Éstos han tenido como efecto la continua, aunque imperceptible, remodelación de las formas glaciares y periglaciares heredadas de los periodos fríos del Cuaternario. La evolución del hielo fósil instalado en el antiguo circo del Corral del Veleta ha deparado la reciente desaparición del antiguo glaciar por reducción de la masa helada (Gómez et al., 2004). Este proceso aparece ligado a la evolución reciente del clima de la montaña, que ha condicionado el tránsito desde condiciones morfogenéticas glaciares a periglaciares. Igualmente se han detectado algunos cambios en los ecosistemas ligados a una posible subida de las temperaturas que enlazaría con el fenómeno de cambio global que afecta a las montañas en todo el mundo (Gómez et al., 2008; Vitousek, 1994).

En relación con ello los estudios realizados por Molero y colaboradores (2010) a partir de observaciones que se ajustan al protocolo GLORIA, llegan a dos conclusiones importantes en relación con la evolución reciente del paisaje vegetal. En primer lugar, el piso biogeográfico más frío ocupa en Sierra Nevada un área de menor extensión de la esperada, lo que demuestra una disminución del área afectada por condiciones térmicas extremas y un aumento de la fragilidad de las comunidades vegetales que viven en la zona culminar de Sierra Nevada. En segundo lugar, se ha observado un predominio del pastizal de Festuca indigesta en el piso oromediterráneo en detrimento de la comunidad clímax de Genista bética. Esta menor representación de las formaciones climácicas del matorral oromediterráneo, denominadas localmente piornal, nos habla de un proceso de pérdida de calidad ambiental cuyas causas explicativas deben ser aún estudiadas en profundidad.

No obstante, resulta evidente que parte de su reducción superficial se debe a la fuerte incidencia de los procesos de reforestación con coníferas. Las masas de pinar, ausentes por completo en los años 50, se extienden en la actualidad sobre un 11,8\% (figura 4) de la superficie total de esta unidad, protagonizando el $75,2 \%$ de todas las dinámicas de cambio (figura 6). 
Figura 4

COBERTURAS DEL SUELO EN LOS PAISAJES NATURALES DE LAALTA MONTAÑA EN 1956 Y 2006

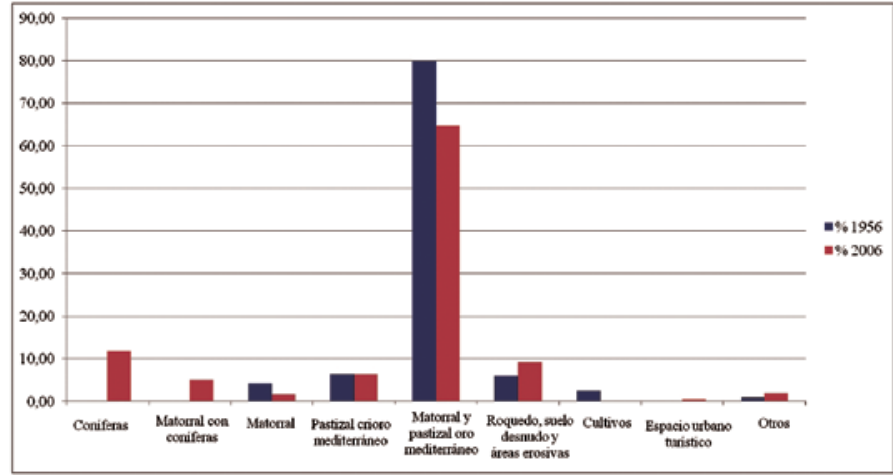

Figura 5

COBERTURAS DEL SUELO EN LOS PAISAJES NATURALES DE LAALTA MONTAÑA EN 1956 Y 2006

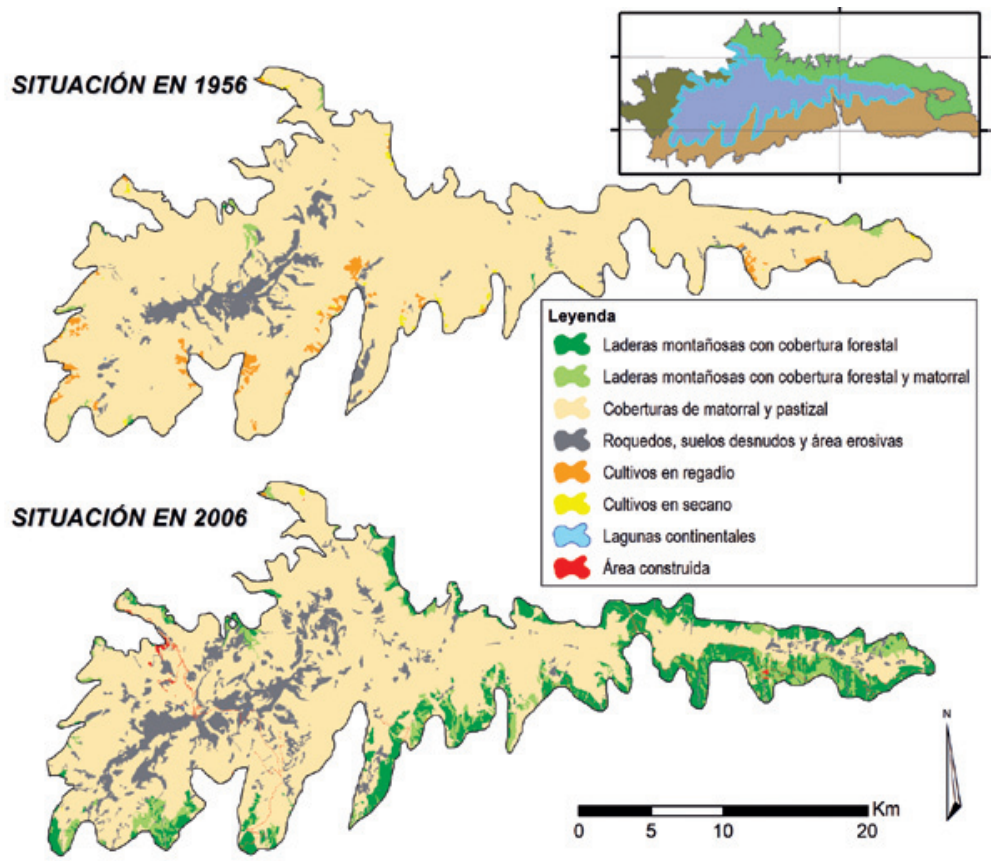

En sentido inverso se han comportado los cultivos de altura o cultivos de sierra que, habiendo penetrado en la alta montaña bajo las condiciones extremas que imponía el modelo económico de subsistencia, aparecen hoy abandonados y en proceso de colonización vegetal.

Por lo que se refiere a la actividad humana, en estos parajes hay que señalar el progresivo desarrollo de los deportes de invierno que vienen concentrando sus instalaciones en los altos 
valles del río Monachil y Dílar. La estación de esquí de Sierra Nevada está asociada a un espacio urbanizado que comenzó a desarrollarse en los años 60 y que hoy ya alcanza 82,5 ha. Además de las agresiones de la urbanización, los ecosistemas de alta montaña han sido intervenidos en toda la superficie acondicionada para la práctica del esquí, aproximadamente 224,7 ha.

La importancia creciente de esta actividad ha generado tensiones territoriales y situaciones de conflicto entre aquellas iniciativas empresariales dirigidas a propiciar una sustancial ampliación del espacio esquiable y otras fuerzas de carácter conservacionista, representadas por los responsables del Espacio Protegido y parte de la sociedad civil, que pretenden limitar el impacto de este uso.

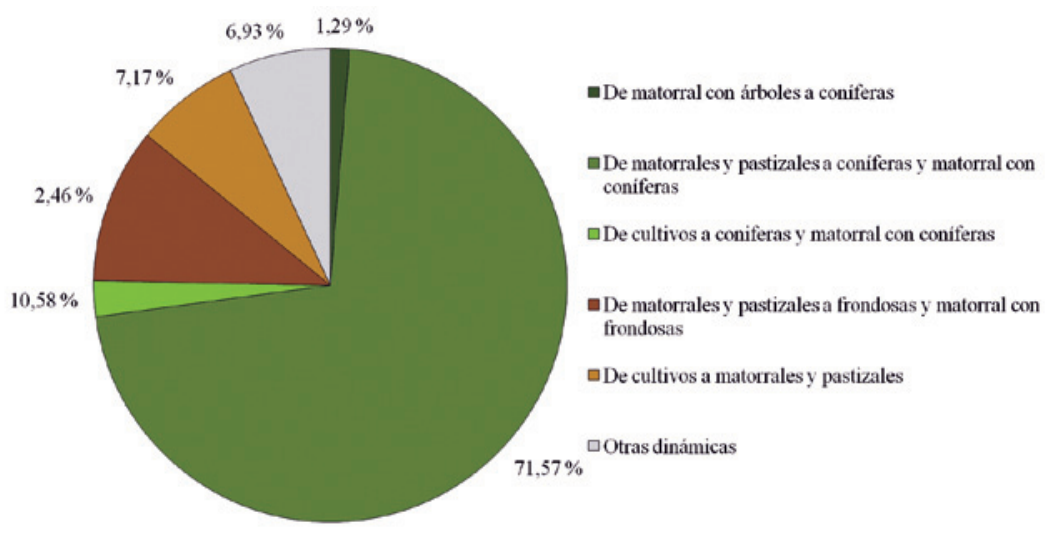

\section{IV.2.2. Los paisajes forestales de las vertientes umbrías}

El nivel de transformación que han conocido los paisajes en la vertiente norte de la Sierra ha resultado extraordinario en el periodo estudiado. Si en 1956 los matorrales y pastizales de degradación de los robledales y encinares meso y supramediterráneos cubrían el $56 \%$ de las laderas, éstos han reducido su extensión drásticamente ocupando hoy apenas el 20\% (ver figura 7). Este proceso de sustitución del monte bajo ha sido el principal responsable de la transformación de los paisajes de la umbría, dado que significa el 55\% de todas las dinámicas de cambio identificadas en este ámbito (ver figura 9).

Las formaciones de matorral y pastizal fueron sometidas a un sistemático programa de reforestación iniciado en los años 60 en el marco de la política hidrológico-forestal proyectada a nivel nacional (Améztegui et al., 2010). Resultado de aquella política son los actuales bosques de coníferas que forman parte de todos los geosistemas de las laderas septentrionales del macizo, si bien su presencia resulta mucho más rotunda en el sector central de esta área (ver figura 8). La introducción masiva de pinos (Pinus pinaster, Pinus sylvestris y Pinus laricio) ha transformado también importantes superficies con arbolado disperso de encinas, generando masas compactas de carácter mixto en donde el proceso de sucesión natural que podría haberse producido de forma espontánea se vio intervenido de manera drástica (Robledo et al., 2009). 
Figura 7

COBERTURAS DEL SUELO EN LOS PAISAJES FORESTALES DE LAS VERTIENTES UMBRÍAS EN 1956 Y 2006

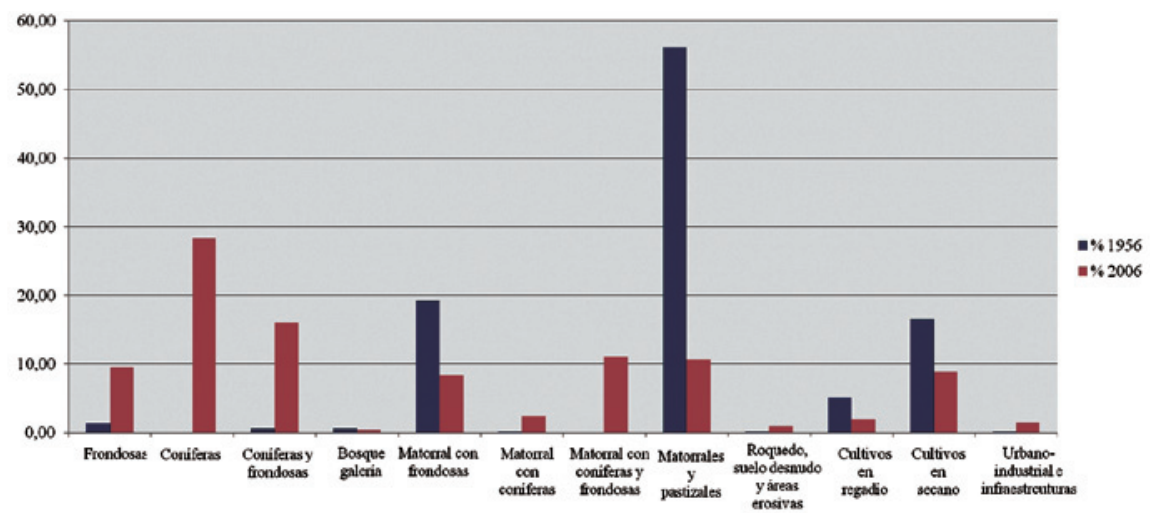

A pesar de esta práctica invasiva y calculada de especies de crecimiento rápido, también podemos distinguir hoy avances importantes de la superficie arbolada tras un proceso natural de sucesión de las comunidades vegetales. El avance de ciertas formaciones hacia la clímax potencial ha permitido la extensión y consolidación de importantes masas de bosque autóctono en el geosistema más húmedo, el que ocupa el extremo occidental de la umbría. En este caso hay que reconocer la influencia decisiva del modelo de aprovechamiento de estos valles, dedicados a la cría extensiva de toros bravos, en la evolución del paisaje. Hoy, la propiedad de estas grandes dehesas, ha pasado a manos del Espacio Protegido, de modo que su conservación parece asegurada.

Los procesos de sucesión vegetal pueden reconocerse en todos los geosistemas de la vertiente norte. Su importancia se demuestra en el hecho de que el 15,3\% del espacio transformado en el último medio siglo corresponde a laderas que estuvieron cubiertas por matorrales y pastizales y en las que hoy encontramos bosques de frondosas y masas de monte bajo con encinas más o menos dispersas.

La tercera dinámica de cambio tiene que ver con el proceso de abandono de las tierras de cultivo y su reconversión. Los cultivos en secano han perdido protagonismo en estos paisajes al desaparecer la mitad de la superficie que ocupaban en 1956. Los antiguos campos de cereal aparecen cubiertos por comunidades pioneras de matorral y pastizal que colonizan hoy el suelo difuminando las viejas estructuras del entramado agrícola. No es extraña la presencia de encinas dispersas por los antiguos terrenos cultivados que colaboran en el proceso de regeneración de la vegetación potencial, ya que resultaba frecuente que algunos de estos árboles ya conviviesen con los cultivos en los años 50 .

Los procesos de recesión y extensificación de la actividad agraria presentan además otras manifestaciones. En buena parte estos terrenos se han visto alcanzados por las actividades de reforestación, de modo que antiguos campos pueden aparecer hoy cubiertos por el pinar. En otros se ha producido la transformación de algunos espacios tradicionalmente regados en terrenos de cultivo de almendros y olivos en régimen de secano, cuyo mantenimiento reclama menor grado de dedicación. No obstante, hemos podido reconocer también algunas dinámicas de expansión agrícola en tanto que unas pocas superficies de almendral y olivar han sustituido superficies de monte bajo. 
Como resultado de todas estas transformaciones los paisajes de media montaña de la vertiente norte de la Sierra, desde los más húmedos del extremo occidental hasta los más áridos del este, adquieren carácter forestal, limitándose la intervención de las poblaciones campesinas al piedemonte.

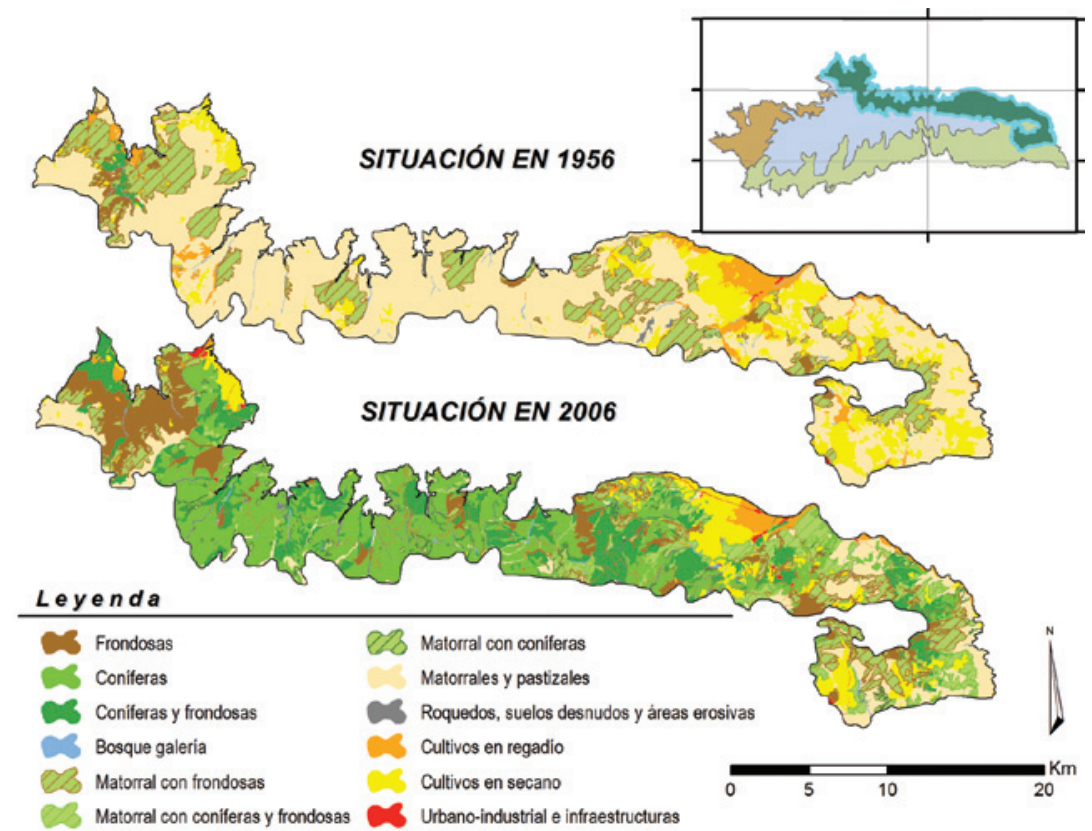

Figura 9

PRINCIPALES DINÁMICAS DE CAMBIO EN LOS PAISAJES FORESTALES

DE LAS VERTIENTES UMBRÍAS ENTRE 1956 Y 2006

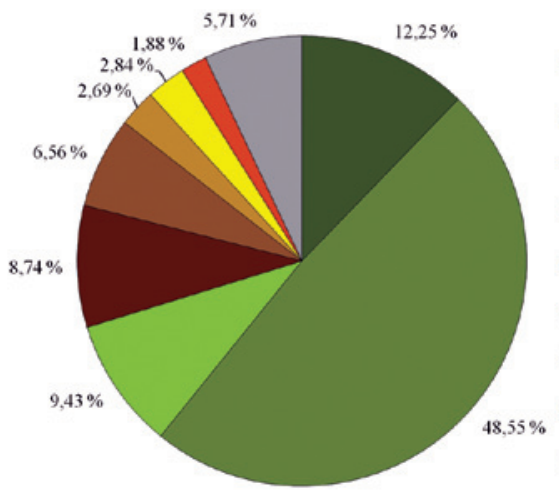

- De matorral con àrboles a coniferas

De matorrales y pastizales a coniferas y matorral con coniferas

a De cultivos a coniferas y matorral con coniferas

- De matorral con árboles a frondosas

- De matorrales y pastizales a frondosas y matorral con frondosas

De cultivos a frondosas y matorral con frondosas

口De cultivos a matorrales y pestizales

- Cambio en el tipo de cultivos

otras dinámicas 


\section{IV.2.3. Los paisajes calcáreos y agro-forestales de los valles occidentales}

Los paisajes del sector occidental de Sierra Nevada han registrado una transformación intensa que afecta al 72,7 \% de su superficie. En el caso de los paisajes calcáreos, que ocupan la mayor parte de este ámbito, las laderas de rocas poco cohesionadas y fuertes pendientes se caracterizan, como antaño, por la virulencia de las dinámicas de erosión del suelo, y en general por el predominio de los procesos denudativos sobre los de edafización y colonización vegetal. Las formaciones calizo-dolomíticas, muy tectonizadas, han generado una morfología muy agreste dominada por relieves caóticos, desfiladeros y gargantas profundas en los cauces de ríos y arroyos. Sobre las laderas es frecuente encontrar un manto de arenas blancas, casi desnudas, que constituyen sustratos móviles muy difíciles de colonizar por la vegetación.

Figura 10

COBERTURAS DEL SUELO EN LOS PAISAJES CALCÁREOS YAGRO-FORESTALES

DE LOS VALLES OCCIDENTALES EN 1956 Y 2006

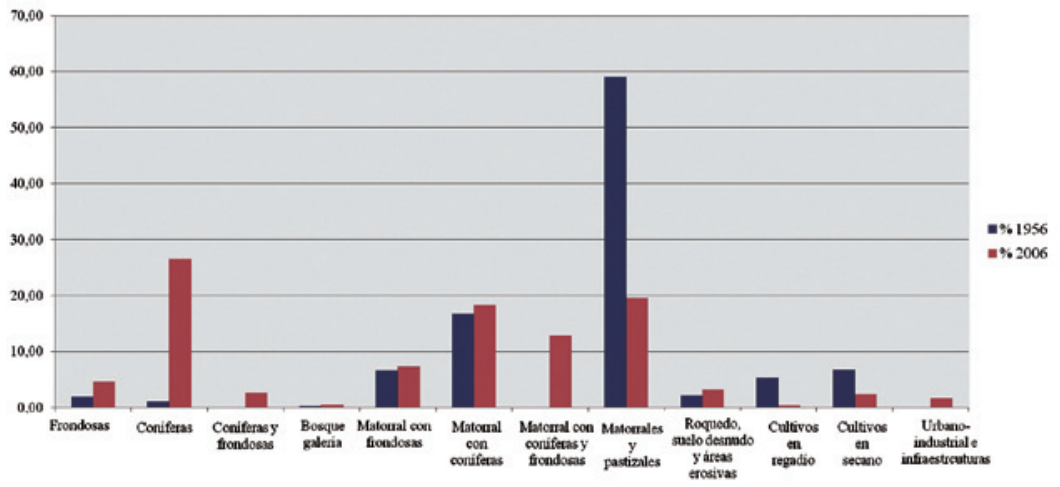

Los cambios que hemos podido constatar en este tipo de paisaje tienen que ver fundamentalmente con la gran extensión que han alcanzado las masas de coníferas (ver figuras 10 y 12). Los bosques de pino silvestre (Pinus sylvestris, var. nevadensis) presentaban un carácter relicto en los años 50 (ver figura 11). Las distintas formaciones de matorral y pastizal, en convivencia o no con ejemplares de pino silvestre, constituían la cobertura más habitual. Tras la puesta en marcha de actuaciones forestales tendentes a la recuperación de los pinares autóctonos, el paisaje actual se caracteriza por la gran extensión de repoblaciones que engloban por completo a las masas relictas, pasando del 17,8\% al 60,3\% de la superficie.

Cabe destacar también el crecimiento espontáneo de frondosas hasta formar bosquetes de encinas y robles, fundamentalmente en las zonas más elevadas de los valles de los ríos Monachil, Dílar y Dúrcal, en el contacto entre las rocas calcáreas y las rocas esquistosas situadas a mayor altura.

La escasa superficie donde el paisaje está ligado a la agricultura tradicional ha disminuido en un $75 \%$, de modo que hoy ocupa sólo el $3 \%$ de la superficie total.

Por su parte, los paisajes agroforestales de la porción noroccidental o cabecera del río Genil, han visto incrementarse la presencia de los elementos forestales al reducirse el espacio cultivado y la presión ganadera. La recuperación de las masas de robles se ha visto fuerte- 
mente impulsada por el cese de cultivos tradicionales como la patata. Al mismo tiempo las terrazas aún cultivadas mantienen su vocación mixta agroforestal y afianzan su especialización hacia la arboricultura de frutales tales como el cerezo, el nogal y el castaño.

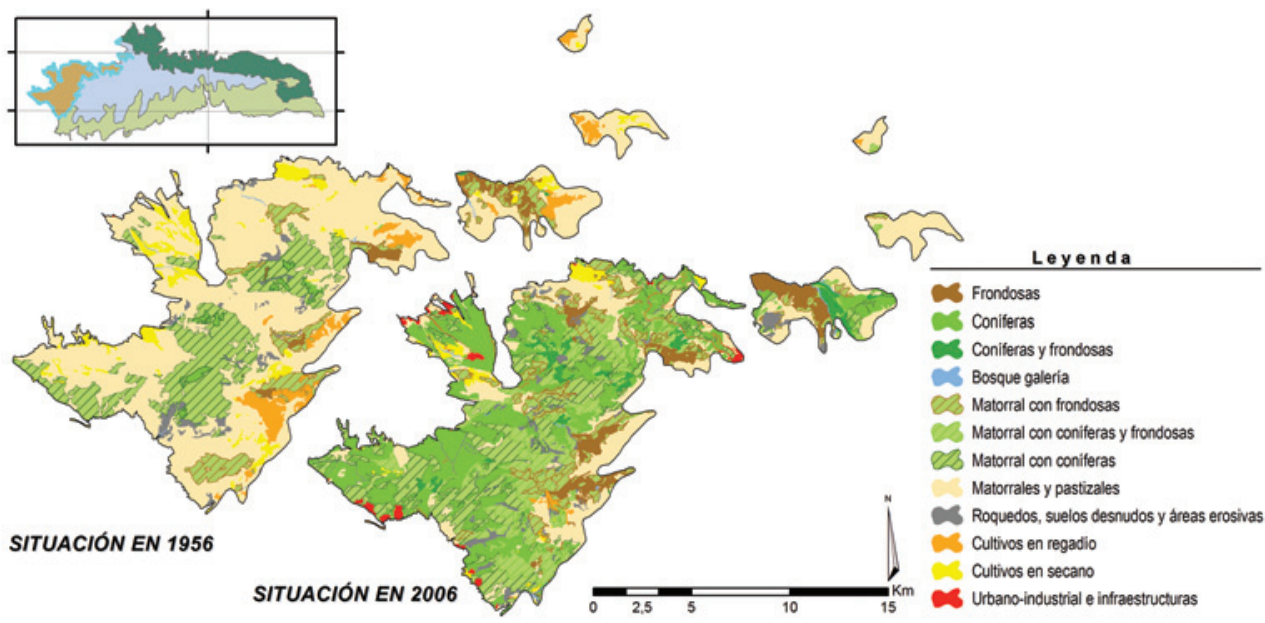

Por último, cabe destacar la importancia que el fenómeno de la urbanización ha adquirido en los bordes y en algunos puntos interiores de este ámbito debido a su vecindad con el área metropolitana de la ciudad de Granada. El sector de piedemonte se ha visto invadido así por nuevas urbanizaciones de primeras y segundas residencias y por actividades ligadas a la construcción como la extracción de áridos. A pesar de que la extensión superficial de estas zonas urbanizadas resulta aún poco significativa, su impacto paisajístico es notable. Además, a partir de estas avanzadillas de lo urbano, se abren vías de penetración para un modelo de evolución del paisaje incompatible con el carácter de área protegida que ampara al conjunto del macizo.

Figura 12

PRINCIPALES DINÁMICAS DE CAMBIO EN LOS PAISAJES CALCÁREOS YAGRO-FORESTALES DE LOS VALLES OCCIDENTALES

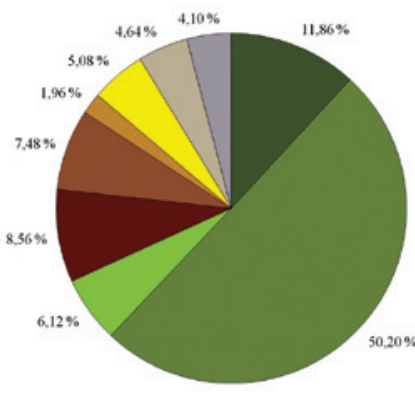

- De matorral con intoles a conifaras

- De matorrales y pastizalesa coniferas y materral eno coniferas

EDe cultivos a coniferas y matorral con coniferas

- De matarral con airboles a frondocar

- De matorrales y pastizalesa frondosas $y$ matorral con froadocas

-De cultivos a frondoses $y$ matorral con frondosas

aDe cultivos a matcoralesy pastizales

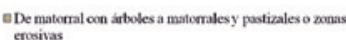




\section{IV.2.4. Los paisajes agro-forestales de la solana}

El nivel de transformación del paisaje alpujarreño resulta inferior al de las comarcas del norte, si bien alcanza al $67,5 \%$ de su superficie.

Los cambios de este paisaje aparecen ligados, en primer lugar, a la evolución que en todos los geosistemas han tenido las geofacies de matorrales y pastizales hacia formaciones arboladas más o menos densas de coníferas y de frondosas, en este caso un 47,8\% de las dinámicas de cambio (ver figura 15). Aunque los programas de restauración forestal no fueron tan extensos como en la umbría, las superficies de pinar, a veces en asociación con encinas, se incrementan significativamente pasando del 1,9 al 20\% de la superficie total del ámbito (ver figura 13).

Figura 13

COBERTURAS DEL SUELO EN LOS PAISAJES AGRO-FORESTALES DE LA SOLANA EN 1956 Y 2006

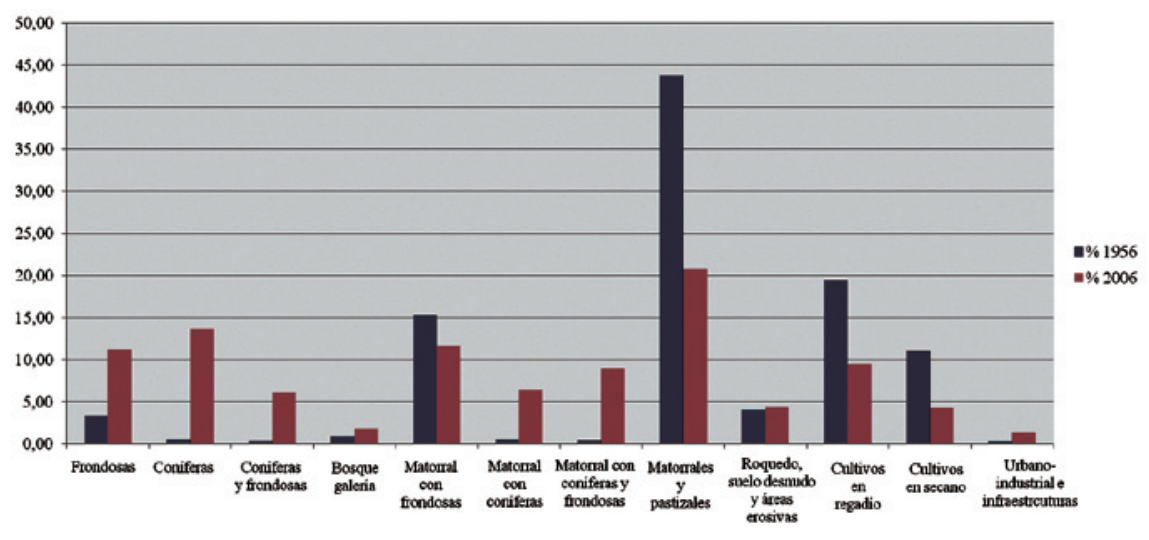

Esta transformación del monte bajo se debe también en gran medida al progreso de la sucesión vegetal hacia estados más maduros y por tanto hacia masas arboladas de frondosas en formación abierta o masas compactas de encinar y robledal, suponiendo un $20,2 \%$ de las dinámicas de cambio. Las formaciones densas, que ocupaban un escaso 3,3\%, pasan a extenderse por un $11,1 \%$ de las laderas solanas. Además, parte de los pinares de reforestación son en realidad comunidades mixtas en donde la encina tiene una importante significación.

En segundo lugar, el comportamiento dinámico-evolutivo de los paisajes de la vertiente sur es provocado por el intenso proceso de abandono de la actividad agraria y la transformación del espacio cultivado, que ha visto reducirse su superficie en un 55\%. En una primera etapa de colonización estos campos son cubiertos por comunidades de matorral y pastizal $(27,6 \%)$. Coberturas arbóreas más o menos densas colocan a otros terrenos en un estadío superior del proceso de sucesión $(30,1 \%)$, normalmente vinculado a la estrecha convivencia de los campos con retazos de vegetación natural o especies forestales que se insertaban en el propio espacio labrado. Igualmente las reforestaciones han reconfigurado un 11,4\% del antiguo espacio agrícola.

El área que se ha mantenido como espacio cultivado también ha conocido cambios de diversa índole. La disminución de activos agrarios y del valor de la producción ha inducido a la adopción de cultivos que permitan una dedicación a tiempo parcial. Así, muchas de las 
tierras dedicadas a la producción de herbáceos, de cereal u hortícolas han sido sustituidas por plantaciones de árboles, fundamentalmente olivos y almendros, y, en menor medida, nogales, cerezos y otros frutales.
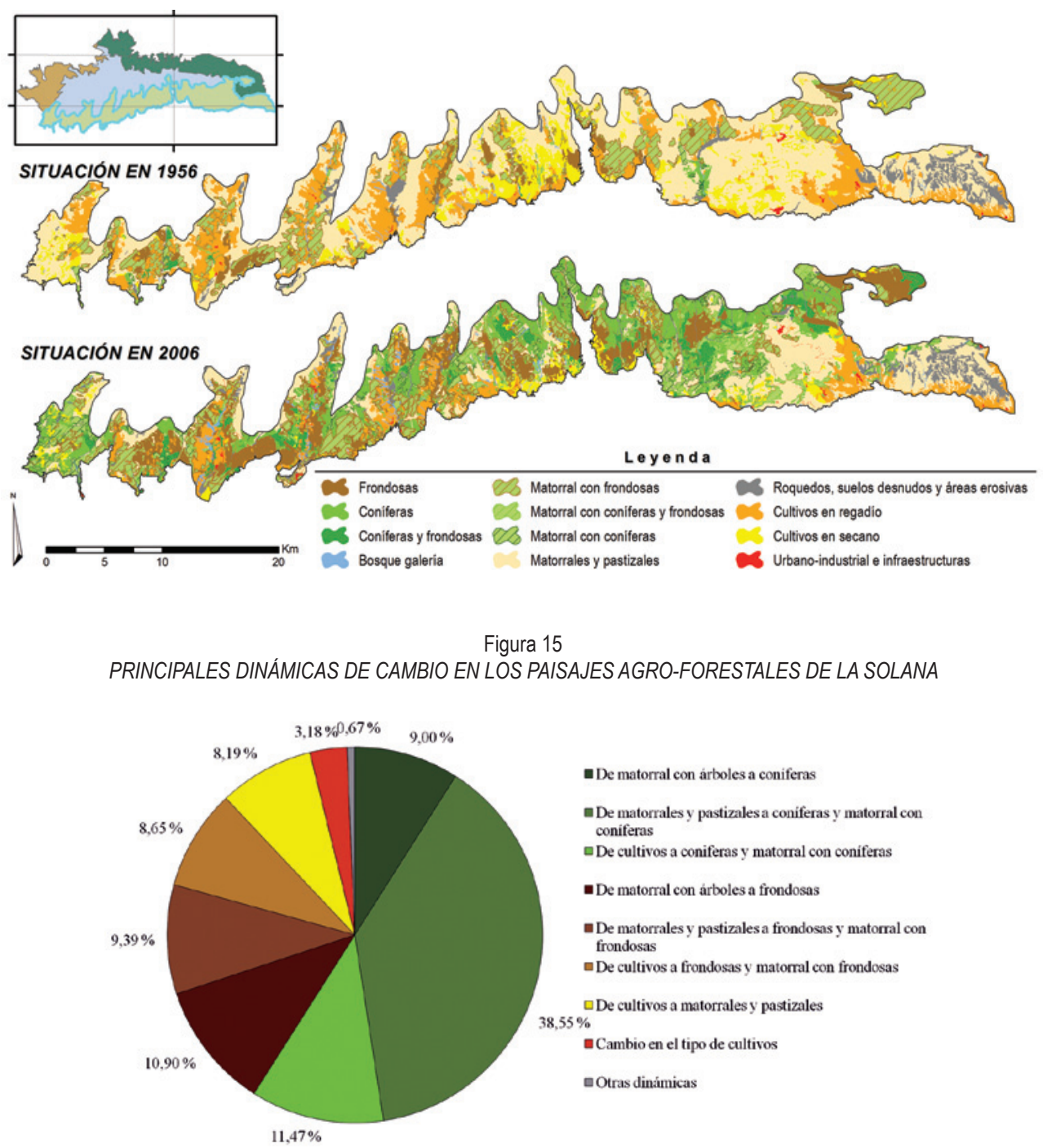

En definitiva los paisajes actuales se componen de mayores extensiones de coníferas de carácter artificial que contrastan con las crecientes masas de encinas y robles, cuyo mayor valor ecológico se demuestra también en su aspecto más natural y armonioso (ver figura 14). Los 
paisajes culturales ligados al manejo agrícola sufren un declive acentuado que tiene su expresión en el mayor aspecto xérico del espacio cultivado, en la descomposición del entramado parcelario, el deterioro de las terrazas y de muchos tramos de acequias, y en la matorralización creciente de muchos campos que desdibujan el mosaico ordenado de un paisaje de gran valor histórico, etnográfico y ecológico cuya imagen ha sido y sigue siendo un signo de identidad comarcal.

\section{CONCLUSIONES}

Las cinco décadas estudiadas han deparado grandes transformaciones en los paisajes de Sierra Nevada mediante dinámicas de cambio muy activas. Según hemos podido medir a partir de la fotointerpretación, los cambios experimentados por los paisajes afectan al 42,8\% de la superficie del Espacio Protegido.

La principal transformación ha sido el sustancial incremento de la superficie forestal, en los cuatro grandes tipos de paisaje identificados. Esta dinámica es resultado de un doble efecto. Por una parte, el de las políticas de reforestación mantenidas durante los años 60 y 70 , formuladas en un momento en el que el interés por la rápida generación de extensas masas de bosque no otorgaba suficiente importancia a las comunidades autóctonas. Se favoreció así la extensión indiscriminada de las masas de coníferas, que contribuyen hoy a la homogeneización de un paisaje forestal muy artificializado. Esta dinámica no sólo ha tenido una fuerte incidencia morfológica en el paisaje sino que implica también alteraciones de base ecológica.

Por otro lado, la dinámica natural de sucesión de las comunidades vegetales, propiciada por el abandono de las actividades agro-ganaderas en extensas áreas de la sierra, ha deteriorado los paisajes de definición cultural por su falta de manejo o por la intromisión de elementos ajenos.

Los paisajes agroforestales, cuyo origen se remonta al pasado islámico medieval de la Península Ibérica, presentan un elevado valor patrimonial, al que se apela desde un sector creciente de los agentes sociales como argumento para su conservación. Las perspectivas de supervivencia de estos paisajes no parecen sin embargo muy optimistas. El nuevo modelo de desarrollo rural para las zonas de montaña que empieza a configurarse desde las políticas europea, nacional y regional, no contempla de manera decidida la necesidad de sostener unas prácticas agrarias que, en nuestra opinión, han constituido las auténticas bases formativas del paisaje cultural durante siglos.

Por el contrario es el turismo el que consigue un creciente protagonismo entre las actividades que hoy se proponen como grandes alternativas al modelo económico tradicional. Un turismo cuyo principal recurso es sin duda el paisaje agrario de los valles meridionales. Hoy la pervivencia de las terrazas cultivadas, una de las imágenes más vendidas de Sierra Nevada, está en cuestión si consideramos el ritmo de desaparición de las explotaciones y el nivel de envejecimiento de la población activa agraria. Si las actividades agro-ganaderas no juegan un papel relevante en el futuro modelo de desarrollo rural sostenible, la degradación del patrimonio cultural está asegurada.

Sobre el espacio de la alta montaña podemos concluir que las dinámicas registradas son importantes si consideramos que este tipo de emplazamientos suelen registrar notables niveles de estabilidad propios de los llamados paisajes «tranquilos». Desde el punto de vista 
natural aún está por conocer la verdadera significación de una eventual elevación de las temperaturas, lo que actuaría siempre en la dirección de fragilizar unos ecosistemas singulares. Paralelamente las tensiones provenientes de las actividades relacionadas con la práctica del esquí pueden resultar difíciles de controlar.

Todos los cambios que hemos identificado en el paisaje son producto de una profunda transformación del papel que juega la montaña para propios y foráneos. Hoy Sierra Nevada no sólo ofrece una base de sustento directo para las poblaciones que allí habitan, como lo hizo durante siglos, sino que se le reconoce un nuevo papel como fuente de recursos hídricos, área de diversidad biológica, espacio para la recreación y refugio de un excepcional patrimonio cultural. La demanda que se ejerce sobre estos espacios es cada vez mayor, multiplicándose los intereses y funciones que en ellos concurren. Por otra parte, la gestión territorial de Sierra Nevada ya no depende sólo de las decisiones de la población local, cada vez más compete a la administración y responde a intereses extralocales.

Este cambio en el modelo de gestión ha determinado, y lo hará aún más en el futuro, la transformación de los paisajes. Por una parte se acusa el decaimiento del sistema de gestión tradicional por abandono de los campos, reducción del uso y mantenimiento de las infraestructuras de riego, así como por la práctica desaparición de los cuidados culturales del monte. Por otra, la gestión pública de un espacio tan extenso y complejo se muestra insuficiente para enfrentar tareas como la prevención de incendios, el control del uso público-turístico, la naturalización de los espacios reforestados, el mantenimiento de las acequias, el control de la fauna salvaje o el impulso de actividades sostenibles en las poblaciones del Espacio Natural Protegido.

Por último cabría señalar que un esfuerzo adicional de coordinación entre las administraciones responsables de la conservación, los agentes del desarrollo local y la población de la montaña, podría favorecer el impulso de un modelo de desarrollo verdaderamente sostenible que permitiese una mejora de la calidad paisajístico-ambiental de los espacios naturales así como la supervivencia de los paisajes culturales, ya que ambos extremos sustentan los principales valores del territorio.

\section{REFERENCIAS}

ALARIO, M., BARAJA, E. y SILVA, R. (2011): «Medio siglo de transformaciones agrarias en España. Factores económicos, sociales y políticos como clave de la dinámica de los paisajes agrarios» en Los paisajes agrarios de España. Caracterización, evolución y tipificación (Molinero, F. et al., coords.). Ministerio de Medio Ambiente Rural y Marino, 127-144.

AMÉZTEGUI, A., BROTONS, L. y COLL, L. (2010): «Land-use changes as major drivers of mountain pine (Pinus uncinata Ram.) expansion in the Pyrenees». Global Ecology and Biogeography, $\mathrm{n}^{\circ}$ 19, 632-641.

ARAQUE JIMÉNEZ, E. (2013): «Evolución de los paisajes forestales del Arco Prebético. El caso de las Sierras de Segura y Cazorla». Estudios Regionales, n 96, 321-344.

ARNÁEZ, J., LASANTA, T., ERREA, M.P. y ORTIGOSA, L. (2010): «Land Abandonment, Landscape Evolution and Soil Erosion in a Spanish Mediterranean Mountain Region: the Case of Camero Viejo». Land degradation \& development, vol. 22, $\mathrm{n}^{\circ}$ 6, 537-550. 
AUGUSTIN, N.H., CUMMINS, R.P. y FRENCH, D.D. (2001): «Exploring spatial vegetation dynamics using logistic regression and a multinomial logit model». Journal of Applied Ecology, $\mathrm{n}^{\circ}$ 38, 991-1006.

BERTRAND, G. (2008): «Un paisaje más profundo. De la epistemología la método». Cuadernos geográficos, $\mathrm{n}^{\circ}$ 43, 17-27.

CALATRAVA, J. y SAYADI, S. (2004): «Permanencia de la actividad agraria y políticas de desarrollo rural: un análisis a partir de un seguimiento (1981-2001) a explotaciones agrarias en zonas de montaña del sureste español». Estudios Agrosociales y Pesqueros, $\mathrm{n}^{\mathrm{o}} 204,207-218$.

CASTILLO MARTÍN, A. (2010): «El papel de las surgencias en los regadíos de Sierra Nevada» en El agua domesticada. Los paisajes de los regadíos de montaña en Andalucía (Guzmán y Navarro, Coord.).Sevilla, ed. Junta de Andalucía, 80-83.

CONSEJERÍA DE MEDIO AMBIENTE DE LA JUNTA DE ANDALUCÍA (2007): Impacto socioeconómico del espacio natural protegido Sierra Nevada. Granada. Consejería de Medio Ambiente de la Junta de Andalucía y ESECA.

CÓZAR VALERO, M.E. (2000): «Los recursos humanos en un espacio natural protegido: Sierra Nevada». Cuadernos Geográficos de la Universidad de Granada, no 30, 325-346.

FOX, J. y VOGLER, J.B. (2005): «Land-Use and Land-Cover Change in Montane Mainland Southeast Asia». Environmental Management, vol. 36, nº 3, 394-403.

GARCÍA, E. y OCAÑA, C. (1990): «L'evolution récente des montagnes meridionales de l'Andalousie». Revue Géographique des Pyrénées et du Sud-ouest, n 61-2, 217-236.

GARCÍA MARTÍNEZ, P. (1999): La transformación del paisaje y la economía rural en la Alta Alpujarra occidental. Granada. Universidad de Granada e Instituto de Desarrollo Regional.

GIMÉNEZ FONT, P. (2008): Las transformaciones del paisaje valenciano en el siglo XVIII. Una perspectiva geográfica. Valencia. Alfons el Magnànim.

GÓMEZ MENDOZA, J. (Dir.) (1999): Los paisajes de Madrid: naturaleza y medio rural. Ed. Alianza y Fundación Caja Madrid. Madrid.

GÓMEZ A., SCHULTE L., SALVADOR F., PALACIOS D., SAN JOSÉ J.J. y ATKINSON A. (2004): «Deglaciación reciente de Sierra Nevada. Repercusiones morfogenéticas, nuevos datos y perspectivas de estudio futuro». Cuadernos de Investigación Geográfica, $\mathrm{n}^{\circ}$ 30, 147-168.

GÓMEZ, F.J., BOADA, M. y SÁNCHEZ, S. (2008): «Análisis de los procesos de cambio global: el caso del robledal de Ridaura (Parque Natural del Montseny. Barcelona)». Boletín de la Asociación de Geógrafos Españoles., n 47, 125-141.

GUILLERME, S., JIMÉNEZ, Y. y MORENO, D. (2013): «Les paysages d'arbres hors forêt, des paysages porteurs des enjeux du développement durable» en Paysage et developpement durable (Luginbühl, Y. et al.). Éditions Quae, 34-47.

HERNÁNDEZ, M. y GIMÉNEZ, P. (2011): Fundamentos históricos de los paisajes agrarios de España en Los paisajes agrarios de España. Caracterización, evolución y tipificación (Molinero, F. et al., Coords.). Ministerio de Medio Ambiente Rural y Marino. 110-126.

IGLESIAS CASADO, A. (1985): «Repoblación forestal» en Sierra Nevada y la Alpujarra (Ferrer, M.). Granada, Ed. Anel, 669-697. 
JIMÉNEZ OLIVENCIA, Y. (1991): Los paisajes de Sierra Nevada. Cartografía de los Sistemas Naturales de una montaña mediterránea. Granada. Monografía Tierras del Sur, Universidad de Granada.

JIMÉNEZ OLIVENCIA, Y. (2010): «Consecuencias del abandono del regadío en la montaña mediterránea» en El agua domesticada. Los paisajes de los regadíos de montaña en Andalucía (Guzmán y Navarro, Coord).Sevilla, Ed. Junta de Andalucía, 508-513.

LAMBIN, E.F., GEIST, H.J. y LEPERS, E. (2003): «Dynamics of land-use and land-cover change in tropical regions». Annual Review of Environment and Resources, vol. 28, 205-241.

LASANTA, T., VICENTE-SERRANO, S.M. y CUADRAT, J.M. (2005): «Mountain mediterranean landscape evolution caused by the abandonment of traditional primary activities: a study of the Spain Central Pyrenees». Applied Geography, n 25, 47-65.

LÓPEZ ONTIVEROS, A. (2004): «Descubrimiento y conformación histórica de los paisajes rurales» en Naturaleza y cultura del paisaje (Ortega Cantero, N., coord.). Fundación Duques de Soria. UAM, Madrid.123-148.

MATA OLMO, R. (1997): «Paisajes y sistemas agrarios españoles» en Agricultura y sociedad en la España contemporánea (González, J.J. y Gómez, C., Eds.). Madrid.

MATA OLMO, R. y SANZ HERRÁIZ, C. (2003): Atlas de los paisajes de España. Madrid. Ministerio de Medio Ambiente.

MOLERO, J., FERNÁNDEZ, M. R., MERZOUKI, A., CASARES, M. y GONZÁLEZTEJERO, M. R. (2010): «Escenarios fitocenológicos de observación para el seguimiento del cambio climático en Sierra Nevada» en Proyectos de investigación en parques Nacionales 2005-2008 (Ramírez, L. y Asensio, B., Eds.). Madrid, Ed. Organismo Autónomo Parques Nacionales Ministerio de Medio Ambiente, 73-96.

MOLINERO, F., OJEDA, J.F., y TORT, J. (Coords.) (2011): Los paisajes agrarios de España. Caracterización, evolución y tipificación. Ministerio de Medio Ambiente Rural y Marino.

MOSCOSO SÁNCHEZ, D.J. (2005): «Desarrollo rural en zonas de montaña. La experiencia de la iniciativa Leader en Sierra Nevada» en Agricultura Familiar en España 2005 (VVAA.). Ed. Instituto de Estudios Sociales Avanzados (IESA), 148-157.

MULERO MENDIGORRI, A. (1995): Espacios rurales de ocio. Madrid. Ministerio de Agricultura Pesca y Alimentación.

OCAÑA OCAÑA, C. (2000): «El espacio rural andaluz, permanencias y cambios de la crisis abierta a mediados de siglo». Cuadernos Geográficos de la Universidad de Granada, ${ }^{\circ}$ 30, 77-95.

PÍÑAR ÁLVAREZ, A. (2008): Nachhaltiges Marketing und Regionalentwicklung in Naturschutzgebieten. Eine Untersuchung am Beispiel der Region Alpujarra in der Sierra Nevada (Spanien). München / Mering: Verlag Rainer Hampp.Zerres, M. (Hg.), Hamburger Schriftenzur Marketing forschung.

ROBINSON, D.T. y BROWN, D.G. (2009): «Evaluating the effects of land-use development policies on exurban forest cover: An integrated agent-based GIS approach». International Journal of Geographical Information Science, $\mathrm{n}^{\circ}$ 23(9), 1211-1232.

ROBLEDO, J. J., NAVASCUÉS, M., GONZÁLEZ, S. C. y GIL, L. (2009): «Introgresión genética en las poblaciones relictas de Pinus sylvestris L. var. nevadensis del Parque 
Nacional de Sierra Nevada» en Proyectos de investigación en parques Nacionales 2005 2008 (Ramírez, L. y Asensio, B., Eds.). Madrid, Ed. Organismo Autónomo Parques Nacionales Ministerio de Medio Ambiente, 73-96.

RODRÍGUEZ MARTÍNEZ, F. (1981): «El papel de la estructura agraria en la crisis de la montaña mediterránea andaluza». En La propiedad rústica en España y su influencia en la organización del espacio (Universidad de Alicante, Departamento de Geografía General, Eds.). Alicante, Universidad de Alicante, 377-390.

RODRÍGUEZ MARTÍNEZ, F. (2000): «Desarrollo rural en las montañas andaluzas. Un análisis desde la sostenibilidad». Cuadernos Geográficos de la Universidad de Granada, $n^{\circ} 30,97-121$.

SWIHART, R.K. y MOURE, J.E. (Ed.) (2004): Conserving biodiversity in agricultural landscapes (Model based in planning tools). Indiana. Ed. Purdue University Press.

TURNER, B.L., MEYER, W.B. y SKOLE, D.L. (1994): «Global Land-Use/Land-Cover Change: Towards an Integrated Study». Ambio, vol. 23, n 1, 91-95.

TURNER, M.G., PEARSON, S.M., BOLSTAD, P. Y WEAR, D.N. (2003): «Effects of land-cover change on spatial pattern of forest communities in the Southern Appalachian Mountains (USA)». Landscape Ecology, ${ }^{\circ}$ 18, 449-464.

VARGA, D. y VILA, J. (2006): «Ecología del paisaje y sistemas de información geográfica ante el cambio socioambiental en las áreas de montaña mediterránea. Una aproximación metodológica al caso de los valles de Hortmoier y Sant Aniol». Areas. Revista Internacional de Ciencias Sociales, $\mathrm{n}^{\circ}$ 25, 59-72.

VILA SUBIRÓS, J., RIBAS, A., VARGA, D. y LLAUSÀS, A. (2009): «Medio siglo de cambios paisajísticos en la montaña mediterránea. Percepción y valoración social del paisaje en la Alta Garrotxa (Girona)». Pirineos, nº 164, 69-92.

VITOUSEK, P.M. (1994): «Más allá del calentamiento global: la ecología y el cambio global». Ecology, no 75(7), 1.861-1.876. Ecology Society of America.

ZOIDO NARANJO, F. (2012): «El paisaje un concepto útil para relacionar estética, ética y política». Scripta Nova, vol. XVI, núm. 407. 